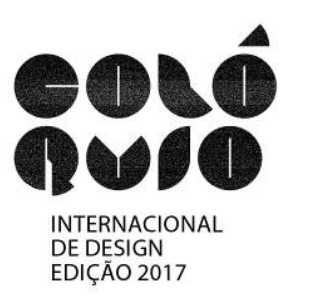

\title{
Biocompósitos de Bambu e Resina de Mamona: Métodos e aplicações no Design de Produtos
}

\author{
João Victor Gomes dos Santos; \\ Giulianna de Moraes Godinho; \\ Marco Antônio dos Reis Pereira
}

resumo:

Em busca da melhoria na qualidade de vida da população e na disponibilidade futura de matéria-prima e energia, os projetos de design têm passado a adotar critérios ecológicos cada vez mais rigorosos em seu desenvolvimento. Um exemplo de prática que vem crescendo paralelamente com o avanço da ciência é o emprego de novos materiais ecologicamente corretos. Além de contribuir com o meio ambiente, esta prática constitui uma excelente ferramenta para a inovação. Neste âmbito, um material que tem despertado interesse mundial de pesquisadores de diversas áreas é o bambu. Sua composição particular, propriedades superiores a vários materiais tradicionais e baixo custo o tornam um excelente material alternativo com forte potencial sustentável e econômico.

Tendo o bambu como material principal deste trabalho, buscou-se desenvolver novos materiais sustentáveis através da produção de dois tipos de biocompósitos de bambu e resina de poliuretano derivado do óleo de mamona. Os biocompósitos foram fabricados utilizando a técnica de Bambu Laminado Colado (BLaC) e uma nova técnica nominada BSFB (Biocompósito Sanduíche de Fibra de Bambu) que se trata de um biocompósito tipo "sanduíche" com laminação manual das fibras obtidas pelo processamento dos resíduos gerados pela fabricação do BLaC. Ambos os biocompósitos utilizaram a resina à base de mamona em sua composição e resultaram em materiais atóxicos, leves, e resistentes; cujo processamento, além de simples e de baixo custo, proporcionou excelente acabamento. Especificamente para este trabalho foram selecionados dois protótipos para exemplificar a aplicação dos biocompósitos, são eles: Protebam - Prótese Transtibial Endoesquelética e a Ocala, uma linha de óculos de sol.

\section{palavras-chave:}

Design; Sustentabilidade; Biocompósitos; Bambu; Mamona 


\section{Introdução}

O intenso uso de materiais não biodegradáveis e não renováveis por setores industriais tem se tornado uma ameaça ao meio ambiente e à disponibilidade futura desses recursos. Essa crescente preocupação acerca das questões ecológicas vem motivando diversas pesquisas relacionadas ao desenvolvimento de novos materiais e processos. Estas pesquisas, por sua vez, resultam em avanços tecnológicos que permitem uma melhoria na função prática de novos produtos (DIAS, 2009). Essa inovação de materiais e processos aliada à aplicação de outras ferramentas de projeto que buscam o desenvolvimento sustentável, pode ser considerada uma ferramenta eficaz no aumento da eficiência ecológica de um determinado sistema.

Segundo Ashby e Jones (2007), países industrializados têm na pesquisa de novos materiais uma grande fonte de desenvolvimento de novas tecnologias no design. A introdução desses novos materiais fomentam novos comportamentos, experiências, arquiteturas e designs de produto, estimulando a inovação nesses ramos (ASHBY e JOHNSON, 2010) bem como a criação de novos empregos e o estímulo da competitividade. Contudo a utilização de um novo material deve ser cuidadosamente acompanhada já que, por ainda não ser completamente caracterizado e conhecido, pode apresentar riscos e falhas no desempenho como uma reação química indesejada ou mesmo desintegrar ao longo do tempo (BEYLERIAN e DENT, 2007). Portanto, é ideal que o material seja analisado, experimentado e caracterizado para que seja empregado de maneira correta de acordo com suas características.

A indústria de criação de bens de consumo exerce papel essencial neste contexto, uma vez que é responsável pela produção da maior parte dos produtos comercializados e consumidos pela população. Portanto, cabe aos designers, engenheiros e demais profissionais atuantes neste setor, a constante avaliação das implicações à segurança e ao meio ambiente que seu projeto possa causar (LÖBACH, 2001). Essa avaliação deve ser constante e deve compreender cada etapa do ciclo de vida desses produtos, da extração da matéria prima ao destino final do produto (LJUNGBERG, 2007).

Logo, faz-se necessária a adoção de técnicas e métodos que orientem o projeto de maneira adequada aos fundamentos do desenvolvimento sustentável como, por exemplo, a metodologia proposta pelo Ecodesign. Fiksel (1996) a descreve como um conjunto de práticas de projeto que tem como propósito a redução dos efeitos negativos de todo o ciclo de vida do produto, que pode ser compreendido pelas etapas de pré-produção, produção, distribuição, uso e descarte. Essas etapas devem ser avaliadas com o constante controle da emissão de substâncias diversas e resíduos que, quando possível, devem ser reintegrados à linha de produção, fechando, assim, o ciclo sustentável em respeito ao meio ambiente, a saúde e a segurança.

Além da responsabilidade ambiental o designer também deve se preocupar com a responsabilidade social inerente aos produtos que desenvolve, buscando a geração de soluções viáveis para populações de baixa renda. Dessa maneira o designer deve sempre promover o equilíbrio entre os três principais requisitos de um produto sustentável: viabilidade econômica, consciência ambiental e a responsabilidade social (LÖBACH, 2001).

Nesta circunstância, além de contribuir com a produção de material científico à cerca do bambu, esta pesquisa de caráter experimental tem por objetivo proporcionar melhor aproveitamento dos resíduos gerados pelo processamento de bambus na oficina da Unesp de Bauru. Através da criação de uma metodologia de processamento de materiais de fonte renovável, buscou-se a criação de biocompósitos atóxicos, biodegradáveis, renováveis e de fabricação simples que foram aplicados na produção de dois protótipos: uma prótese transtibial endoesquelética e uma linha de óculos. Propriedades que, somadas ao seu baixo custo, oferecem as condições ideais para aplicação não somente no setor industrial, mas também no mercado artesanal, favorecendo comunidades e cidadãos que atuam no setor e agregando valor a um material sustentável, de fácil acesso e baixo custo.

\subsection{Bambu}

O bambu é uma planta lenhosa, monocotiledônea pertencente às angiospermas. Pode ser classificado como um material lignocelulósico de rápido crescimento, composto por fibras naturais de elevada resistência e apresenta-se como uma valiosa contribuição na produção de materiais 
alternativos com forte potencial sustentável e também como reforço de matrizes (NELSON, 2013; KHALIL, 2012). Tais características têm despertado interesse para o seu estudo nas áreas de construção civil, arquitetura e design de produtos. Propriedades essas que, se considerada seu processamento e aplicação correta, mostram-se superiores a vários materiais tradicionais como o concreto e diversas espécies de madeira (RIVERO, 2003).

O bambu é constituído por aproximadamente $50 \%$ de parênquima, $40 \%$ de fibras e $10 \%$ de tecidos condutores (LIESE, 1998) e suas propriedades mecânicas estão relacionadas, principalmente, com a espécie, idade e época de corte do colmo, além da maneira como é aplicado e processado (PEREIRA e BERALDO, 2007).

As espécies podem variar de poucos centímetros de altura e talo fino, até 40 metros de altura e diâmetro de mais de 30 centímetros. Os tipos lenhosos geralmente possuem porte arbóreo, sendo constituídos por uma parte aérea, que inclui colmo, folhas, folhas caulinares, ramos, e uma parte subterrânea, composta por rizoma e raízes (GRECO e CROMBERG, 2011).

Pereira e Beraldo (2007) o descrevem como um material leve, resistente, flexível, renovável, biodegradável e de baixo custo que pode ser utilizado nas mais diversas formas, seja em sua forma natural tubular, processado em forma de ripas ou ainda em conjunto com outros materiais como resinas e concreto.

Dentre todas as suas características a que mais se destaca é o seu rápido crescimento. Sendo a planta mais rápida do que qualquer outra do planeta, necessita, em média, de 3 a 6 meses para que o broto atinja sua altura máxima que pode ser de até 30 metros para as espécies gigantes (PEREIRA e BERALDO, 2007). Segundo Beraldo e Azzini (2004) algumas espécies de bambu já podem ser colhidas e utilizadas aos três anos de idade com resistência e durabilidade semelhantes à de madeiras que precisariam do dobro do tempo ou mais para serem cortadas.

Além dos seus benefícios ao meio ambiente, o bambu pode ser considerado um instrumento para o desenvolvimento econômico e social, podendo contribuir para a geração de renda e trabalho para pequenos agricultores através do seu fácil cultivo, processamento e comercialização (BARELLI, 2009).

Apesar da pouca participação do bambu no setor industrial brasileiro, é visível o esforço que órgãos e instituições vêm tomando para explorar este potencial no Brasil. Iniciativas de incentivo ao cultivo do bambu, como a aprovação da Lei $\mathrm{n}^{\circ} 12.484$ (de 8 de Setembro de 2011) e de diversas pesquisas relacionadas ao material vêm fomentando a exploração comercial do bambu e sua contribuição socioambiental.

O que ainda dificulta sua aplicação nos setores industriais é a escassa existência de normas específicas para sua aplicação. Dessa maneira os ensaios físicos e mecânicos ainda são efetuados com aplicação das metodologias e normas referentes à madeira maciça, o que dificulta a comparação dos resultados e a sua aplicação.

\subsection{Resina de Poliuretano à Base de Mamona}

$\mathrm{O}$ poliuretano (PU) à base de óleo de mamona pode ser classificado como uma resina termofixa líquida de baixa a alta viscosidade. Trata-se de um polímero bicomponente composto por um pré-polímero e um poliol extraído do óleo da semente da mamona (Ricinus communis). Por ser proveniente de fonte renovável constitui uma excelente alternativa para o desenvolvimento de biocompósitos, além disso, segundo Godoy (2007), é completamente atóxica por não apresentar materiais voláteis e metais pesados em sua composição e também por não precisar de solventes para aplicação.

Segundo a ASM (American Society for Metals, 2001) as resinas epóxi e poliuretano se destacam entre os polímeros comerciais utilizados como matriz, principalmente na obtenção de compósitos poliméricos reforçados com fibras. A grande variedade de escolha dos reagentes permite a obtenção de diferentes materiais com diferentes propriedades físicas e químicas e a versatilidade, principalmente do poliuretano, permite a obtenção de diversas texturas como espuma, elastômero ou polímero rígido.

A mistura, em temperatura ambiente, entre o poliol à base de mamona e o isocianato (prépolímero) leva à reação de polimerização da mistura cujo tempo de secagem ao toque é de 
aproximadamente 30 minutos e, para cura total, 24 horas dependendo da temperatura e umidade do ambiente. A flexibilidade da resina está diretamente relacionada à proporção do poliol, ou seja, quanto mais poliol mais flexível. Enquanto que, para conferir mais rigidez, aumenta-se a concentração de prépolímero (GODOY, 2007).

Segundo Targa (2011), a interação química dos grupos isocianatos da resina com grupos funcionais presentes nos materiais lignocelulósicos do bambu podem facilitar a adesão interfacial entre estas matrizes e as fibras. Essa melhor adesão permite uma melhor transferência da carga para fibras ao mesmo tempo em que oferece proteção contra abrasão e ataque de agentes externos (MAHAJAN e AHER, 2012). No entanto ao se utilizar fibras vegetais é necessário realizar a secagem das fibras antes do processamento tendo em vista que os grupos isocianatos reagem com as moléculas que contém hidrogênio ativo formando ureia e gás carbônico quando em contato com a água (TARGA, 2011).

\subsection{Biocompósitos de Bambu}

Segundo a ASTM (American Society for Testing Materials, 2007), entende-se como compósito um material formado pela mistura física de dois ou mais materiais, imiscíveis entre si, combinados para formar um novo material útil de engenharia que possui algumas propriedades diferentes em relação aos componentes puros. A fase contínua é denominada matriz que é acrescida de uma ou mais fases dispersas que podem ser utilizadas como reforço, conferindo rigidez e resistência ao material final ou então como enchimento, para reduzir o custo do material (ABMACO, 2009).

No caso dos biocompósitos, segundo Fowler et al. (2006), os componentes são de origem natural e renovável. Como exemplo para a fase dispersa podem ser utilizadas fibras de plantas (algodão, linho e semelhantes), fibras de madeira, entre outros, enquanto que, para a matriz pode-se utilizar polímeros tais como óleos vegetais ou amidos.

O desempenho mecânico dos compósitos é influenciado diretamente pelas propriedades dos materiais que o constituem, bem como sua distribuição, a fração volumétrica dos componentes e sua interação físico-química (TARGA, 2011). Quando reforçados por fibras, além da alta resistência química, alto módulo elástico e resistência à tração específica (AGARWAL e BROUTMAN, 1990) esses compósitos permitem a moldagem de formas complexas que dificilmente podem ser obtidas em outros materiais. Por outro lado, por serem basicamente constituídas por celulose, hemicelulose, lignina e outros compostos orgânicos de estrutura química complexa Al-Qureshi (1997) recomenda que a aplicação desses biocompósitos seja realizada apenas em situações que solicitam baixo esforço mecânico do material, baixa densidade e custo reduzido.

Atualmente, ao se comparar os biopolímeros aos termoplásticos convencionais geralmente seu custo é elevado e suas propriedades inferiores o que tornam sua aplicação menos vantajosa (PELLICANO et al. 2009). Portanto, a criação de biocompósitos com inserção de fibras vegetais em matrizes poliméricas, além de benéfico ao meio ambiente, pode ser uma alternativa para melhorar as propriedades do material e ao mesmo tempo reduzir o custo tornando-os competitivos em relação aos materiais convencionais.

De acordo com a ASM (2001), o melhor desempenho mecânico é apresentado pelos polímeros reforçados por fibras contínuas (longas) por terem propriedades anisotrópicas, ou seja, possuem alta resistência à tração na direção paralela às fibras. Contudo, apresentam baixo desempenho mecânico quando as forças são aplicadas perpendicularmente às fibras, sendo atuantes, neste caso, as propriedades da matriz. Portanto, apesar de possuir menor reforço se comparadas às fibras contínuas, para aplicações cujas forças são atuantes em direções distintas, é recomendado o uso de polímeros reforçados por fibras descontínuas (curtas), ou seja, isotrópicos.

\subsection{Bambu Laminado Colado (BLaC)}

Dentre as inúmeras técnicas de fabricação de chapas de bambu de países como a China, Índia e Vietnã a mais popular é a conhecida como Bambu Laminado Colado. Apesar de muito popular nesses países, no Brasil e em outros países da América Latina sua popularização se deu somente nos últimos 
anos com a importação desses produtos e adaptação das tecnologias para produção local (PEIXOTO, 2010).

O BLaC pode ser descrito como um compósito de lâminas finas de bambu coladas paralelamente que podem ser curvadas pela ação de moldes do tipo macho e fêmea. Devido à sua versatilidade o BLaC pode ser um substituto da madeira e de outros diversos materiais seja na confecção de utensílios simples como tábuas de carne até estruturas residenciais complexas.

Para confecção das lâminas de bambu são necessários bambus de grande porte e de parede espessa como a espécie Dendrocalamus asper, que, segundo Talabgaew e Laemlaksakul (2007), é a mais recomendada para este fim. Os colmos devem ser colhidos com mais de três anos de idade e deve ocorrer preferencialmente durante a estação seca (Maio a Agosto) que, por conta do teor reduzido de seiva dos colmos, reduz o ataque de fungos e insetos (PEREIRA e BERALDO, 2007). Depois de colhidos os colmos devem passar por um processo de secagem em local coberto e ventilado até atingir a umidade ideal de 10 a $15 \%$. Este processo varia conforme a umidade do ar, idade do colmo e época do ano, podendo levar de um a quatro meses (BERALDO e AZZINI, 2004).

Após esse período de secagem os colmos são então processados em lâminas mantendo a região mais próxima à casca pela maior concentração de fibras. $O$ agrupamento de lâminas, preferencialmente com teor de umidade entre $13 \%$ e $20 \%$ (HIDALGO-LÓPEZ, 2003), pode ser colado face-a-face ou lado-a-lado com algum adesivo ou resina e é então prensado com moldes lineares ou curvos, sendo esse último preferencialmente com aquecimento de $60^{\circ} \mathrm{C}$ a $90^{\circ} \mathrm{C}$ (IRVIN, 1980). Os moldes aquecidos afrouxam a lignina presente entre as fibras do bambu e facilita a curvatura do material em ângulos que a maioria das espécies de madeiras não suporta (RAMOS, 2014). Após a cura do adesivo o BLaC é retirado do molde e pode ser processado normalmente com emprego de técnicas convencionais de marcenaria e usinagem.

Pereira e Beraldo (2007), Rivero (2003) e outros diversos autores recomendam a aplicação do $\mathrm{BLaC}$ no design de produtos pela sua versatilidade, baixo custo, resistência e também pelo seu excelente acabamento.

\subsection{BSFB - Biocompósito "Sanduíche" de Fibra de Bambu}

Quando um compósito é submetido a uma determinada carga, além das propriedades dos materiais que o constitui, a disposição e a estrutura desses materiais também podem influenciar o seu desempenho. Segundo Gagliardo e Mascia (2010) nos compósitos do tipo sanduíche os materiais, de propriedades diferentes, porém complementares, são dispostos em duas ou mais camadas, resultando em um novo material estruturalmente mais eficiente. As faces do compósito suportam as tensões normais de tração, compressão ou cisalhamento quando flexionado, enquanto que o núcleo, ou recheio, mantém as faces afastadas. O núcleo, portanto, deve ser rígido o bastante no sentido perpendicular às faces para e evitar esmagamento e o cisalhamento transversal (TITA, 2007 apud GAGLIARDO E MASCIA, 2010). Ainda segundo os autores, essa técnica é empregada quando há necessidade de se fabricar compósitos resistentes, duráveis e de baixo peso. O uso deste método vem se expandindo principalmente pela sua eficiência em transferir cargas de flexão e compressão, e pela sua capacidade de combinar alta rigidez a flexão e baixo peso.

As fibras mais comuns aplicadas nesses tipos de compósito são as sintéticas, como a fibra de vidro. Entretanto, de acordo com Silva et al. (2004) as fibras naturais têm demonstrado diversas vantagens quando comparados às fibras tradicionais como baixo custo, baixa densidade, boa tenacidade, boas propriedades térmicas, baixo conteúdo energético e uso reduzido de instrumentos para o seu tratamento ou processamento.

Um obstáculo considerável ao se aplicar as fibras vegetais é a sua alta absorção de umidade que pode resultar em seu inchamento e, consequentemente, perda da estabilidade dimensional dos reforços. No entanto, Carvalho (1996) ressalta que essa absorção de umidade é minimizada pelo recobrimento e boa adesão da fibra com a matriz. Nelson et al. (2003) reforçam essa afirmação ao considerarem apropriada a interação entre a fibra de bambu e a resina à base de óleo de mamona. Os autores ainda recomendam, em função das propriedades avaliadas em seus estudos, a 
aplicação dos materiais na produção de biocompósitos ressaltando a elevada capacidade de adesão, as características hidrofóbicas do poliuretano e os benefícios ambientais e econômicos.

\section{Materiais e Métodos}

O colmo de bambu utilizado neste projeto pertence à espécie Dendrocalamus asper, de 4 anos de idade, proveniente do Plantio Experimental da Unesp - Bauru. Após a sua colheita, tratamento e secagem, o colmo foi encaminhado para a Serra Circular onde foi realizado o destopo de acordo com as medidas estipuladas pelos projetos da Prótese e dos Óculos (Figura 1). Imediatamente após o destopo as seções do colmo foram então refiladas na Serra Circular Refiladeira Dupla com aproximadamente $3 \mathrm{~cm}$ de largura. Neste momento, as ripas de bambu possuíam aproximadamente 2,5 $\mathrm{cm}$ de espessura e permaneceram unidas apenas pela protuberância interna do bambu (diafragma) e foram facilmente separadas com as mãos. Os resíduos destes processos foram reservados para obtenção das fibras. As protuberâncias externas (nós) e internas (diafragma) das ripas foram então retiradas na Serra Circular de Bancada. Após esta etapa as ripas foram encaminhadas para a Plaina de Duas Faces (própria para bambu) onde foram beneficiadas com aproximadamente $2 \mathrm{~mm}$ de espessura.

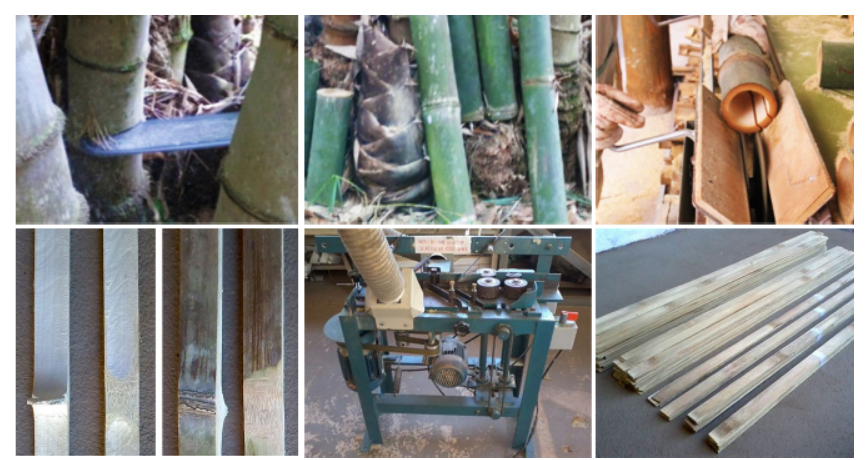

Figura 1 - Processamento do bambu em ripas. Da esquerda para a direita: Colheita, Destopo, Refilamento, Retirada de Protuberâncias, Plaina Duas Faces e Ripas Prontas. (Fonte: adaptado de Ramos, 2014).

Os resíduos gerados por esses processos foram coletados e triturados em um Moinho de Martelos conforme apresentado na Figura 2. As fibras foram então peneiradas em uma Peneira Vibratória Mecânica utilizando a granulometria Tyler/Mesh 16, 20, 28 e 60. Após a separação, as fibras foram secas em uma Estufa Industrial com circulação e renovação de ar forçado por um período de 12 horas a $70 \pm 2{ }^{\circ} \mathrm{C}$ revirando cada 4 horas.
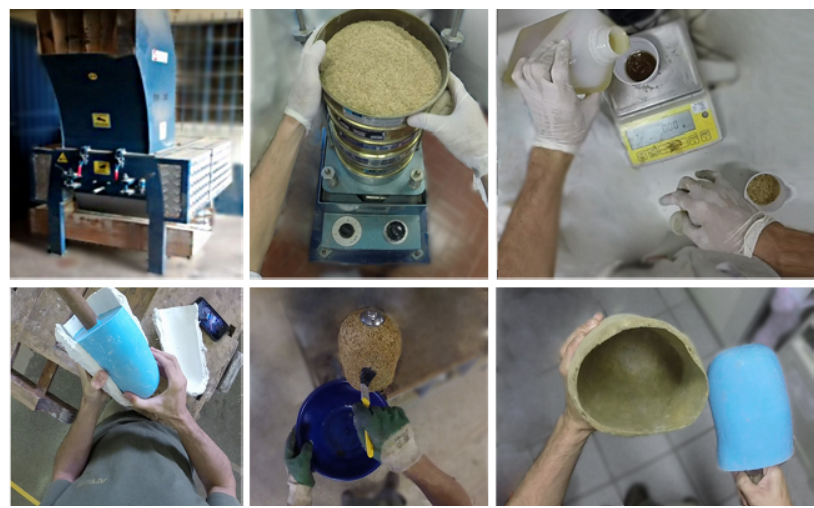

Figura 2 - Produção do BSFB. Da esquerda para a direita: Moinho de Martelos, Granulometria, Pesagem da Resina, Fabricação do Molde, Laminação do BSFB e Retirada do Molde. (Fonte: do autor).

Após o preparo da matéria-prima foi iniciada a fabricação dos produtos. A prótese transtibial utiliza os dois tipos de biocompósito (BLaC para o pé protético e cilindro, e BSFB para o soquete) enquanto que a produção dos óculos necessita apenas do BLaC. O preparo foi iniciado com a pesagem do poliol e do isocianato conforme a proporção 2:1 e misturados manualmente. Utilizando um pincel 
tipo trincha, a mistura foi pincelada nas faces das ripas de bambu de acordo com a orientação da colagem necessária (Figura 4). As ripas foram então unidas, alinhadas e prensadas com grampos barra $\mathrm{T}$ e um torquímetro para regular o torque em $30 \mathrm{Nm}$ (Figura 3). Após o período de 24 horas de cura da resina, os moldes do BLaC foram liberados e as peças foram encaminhadas para as próximas etapas. As chapas dos óculos seguiram para o corte a laser e o bloco para torneamento (Figura 3).

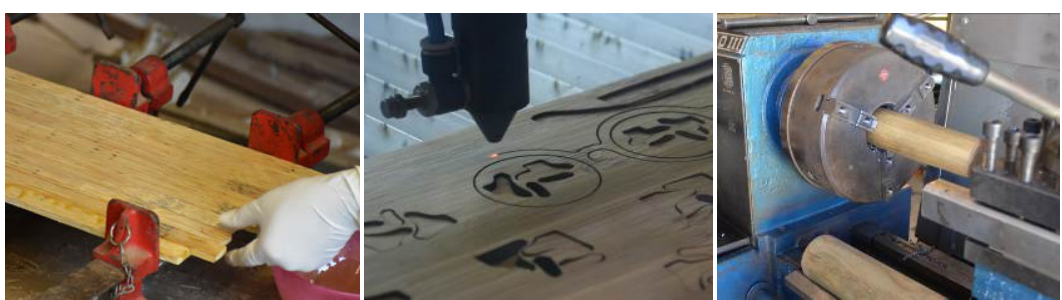

Figura 3 - Fabricação e Processamento do BLaC. Da esquerda para a direita: Prensagem das Lâminas, Corte a Laser e Torneamento. (Fonte: do autor).

Durante este processo o molde positivo de silicone da prótese transtibial, previamente fabricado, também recebeu uma camada da resina e uma camada das fibras de bambu (Tyler 60) laminadas manualmente e prensadas com auxílio de um pincel para melhor adesão das fibras e remoção de bolhas (Figura 2). Além desta camada, esta peça recebeu mais duas camadas de resina e fibra, respeitando o tempo de cura de 24 horas entre camadas. Para a camada central (estrutural) utilizou-se fibras da peneira Tyler 16 e 20 e a camada final, Tyler 60.

Diferente da prensagem do $\mathrm{BLaC}$ utilizado para fabricação dos óculos e do cilindro central da prótese, a prensagem das placas de $\mathrm{BLaC}$ curvo utilizadas para fabricação do pé protético necessitaram de dois moldes térmicos tipo macho-fêmea (Figura 4) fabricados conforme proposto por Ramos (2014). Após a aplicação da resina e pré-aquecimento do molde a aproximadamente $70^{\circ} \mathrm{C}$, as ripas foram coladas, alinhadas e prensadas no molde com auxílio de grampos barra $\mathrm{T}$ com $30 \mathrm{Nm}$ de torque.

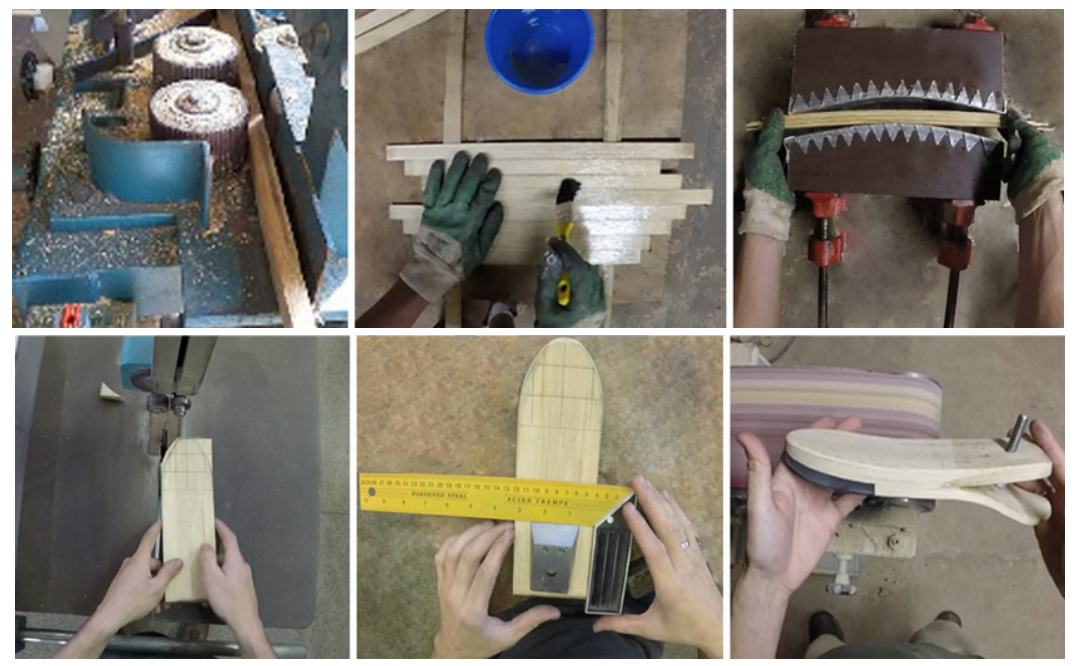

Figura 4 - Fabricação do Pé Protético. Da esquerda para a direita: Plaina Duas Faces, Colagem das Ripas com Resina, Prensagem no Molde Macho-Fêmea, Recorte da Peça, Montagem de Componentes e Acabamento. (Fonte: do autor).

A resistência dos moldes térmicos foi desligada após 30 minutos as peças aguardaram um período de 24 horas para cura completa da resina. Os moldes foram então liberados e as peças cortadas conforme o projeto (Figura 4). Todos os materiais foram então lixados e receberam uma fina camada da resina de mamona como acabamento. Após o tempo de cura do acabamento os protótipos foram finalizados com a montagem de seus respectivos componentes. 


\section{Resultados e Discussão}

Os protótipos resultantes atenderam todas as expectativas iniciais. Os materiais se mostraram compatíveis com sua aplicação proporcionando um acabamento estético excelente. A trabalhabilidade do material se mostrou simples e não houve falhas expressivas.

Durante a produção do BLaC buscou-se a utilização da seção das ripas que não apresentava nós. Por ser um ponto frágil do material, os nós, quando inevitáveis, foram mantidos nas extremidades das peças para evitar concentração de forças em regiões indesejadas. As chapas de BLaC utilizadas para a produção dos óculos foram cortadas à laser com a máquina ECNC L-1060 que possibilitou um excelente aproveitamento da chapa e corte preciso de acordo com as especificações do projeto.

Um ponto importante a se destacar foi o emprego de softwares CAD (Computer Aided Design) no projeto dos protótipos. A utilização dessa tecnologia permitiu o desenvolvimento preciso das peças resultando na prevenção de falhas bem como na compatibilidade entre os componentes produzidos e peças adquiridas no comércio. Além dos benefícios apresentados, a possibilidade de visualizar o produto antes de sua produção já com as texturas do bambu facilitou a análise estética dos modelos antes de sua produção.

Por se tratar de um material barato, a aplicação do bambu possibilitou a redução drástica no custo dos produtos, categorizando os produtos como de baixo custo. Somado a isso, a simplicidade na fabricação dos materiais e ferramentas necessárias os tornam ideais para produção e comercialização por comunidades de baixa renda.

Para comprovar o baixo custo de fabricação, durante a produção da prótese transtibial (Figura 5), o tempo de operação de todas as máquinas foi registrado. Após o cálculo da potência e consumo de energia das ferramentas, foi estimado o custo energético de cada operação. Os dados foram então somados a outros custos da produção do protótipo como mão de obra e de materiais e totalizaram aproximadamente $\mathrm{R} \$ 570,00$ reais, caracterizando a prótese como de baixo custo quando comparada às próteses disponíveis no mercado. Como o custo dos moldes e outros processos primários estão inclusos, ao se escalar a produção, espera-se que este custo seja reduzido ainda mais. Cabe ressaltar também que o depósito de patente da prótese foi realizado pela AUIN (Agência Unesp de Inovação) e encontra-se registrado no INPI (Instituto Nacional de Propriedade Industrial) sob o número BR 10 2016 010161-1.

O protótipo da prótese transtibial comprovou a viabilidade construtiva da prótese e a eficiência do método de fabricação do BLaC proposto por Ramos (2014). A metodologia criada para fabricação do BSFB também se mostrou apropriada, não somente pela reintegração dos resíduos no ciclo de produção, como proposto por Fiksel (1996), mas também pelo biocompósito ter se mostrado um material de fácil laminação, excelente acabamento, e resistência a choques e riscos. No entanto, é importante ressaltar que, por se tratar de um novo material, o BSFB se encontra em fase de testes e ensaios para caracterização do material conforme normas da ASTM. Assim também ocorre com o protótipo da prótese transtibial que ainda encontra-se em fase de análises mecânicas, biomecânicas e reformulações para atender as recomendações da norma ISO 10328:2016.

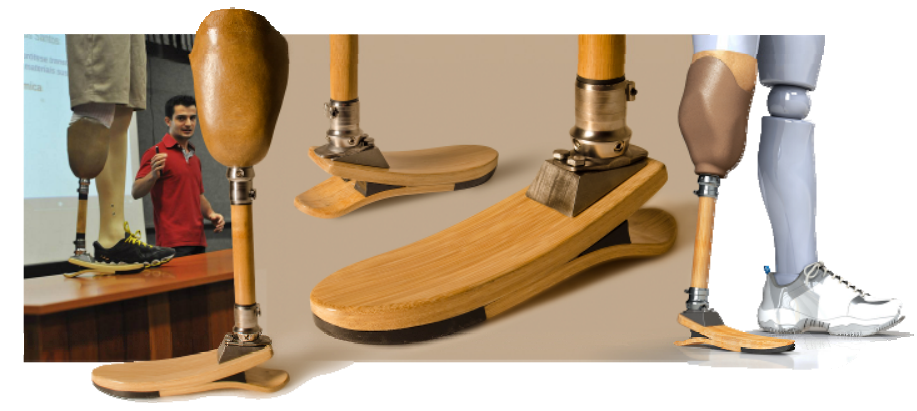

Figura 5 - Fotos e renderizações do protótipo da prótese transtibial endoesquelética - Protebam.

(Fonte: do autor).

Além da proteção e resistência a riscos, o acabamento com a resina também impermeabilizou os produtos visto que, segundo a fabricante $\mathrm{KEHL}^{\circledR}$ - Indústria e Comércio, os testes realizados de acordo com as normas NBR-9779/95 e NBR-10787/94 comprovam a capacidade de impermeabilização das resinas. 
Quanto à produção da linha de óculos Ocala (Figura 6), inicialmente houve problemas durante a colocação das lentes em diversos modelos. O processo resultou em quebras da armação frontal cujas possíveis causas levantadas incluem: utilização da resina de mamona como adesivo, alinhamento das ripas em um único sentido, impermeabilização com cera de abelha (o acabamento com a resina confere mais resistência ao material) e espessura das lâminas. Após os testes concluiu-se que a técnica de 3 camadas de lâminas que totalizaram $5 \mathrm{~mm}$ de espessura e foram alinhadas perpendicularmente é a técnica mais indicada para produção, bem como o acabamento com resina de mamona.

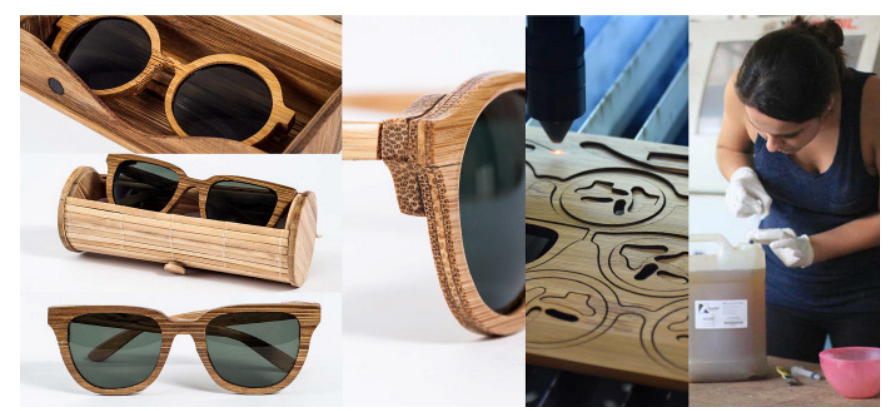

Figura 6 - Fotos da linha de óculos Ocala e processo de produção. (Fonte: www.behance.net/gallery/49728343/Ocala-Bamboo-Sunglasses).

\section{Agradecimentos}

Este trabalho foi realizado com financiamento da Coordenação de Aperfeiçoamento de Pessoal de Nível Superior - CAPES e apoio da KEHL ${ }^{\circledR}$ Indústria e Comércio, de São Carlos - SP, fornecedora da Resina de Mamona.

\section{Biocomposites of Bamboo and Castor Oil Resin: Methods and Applications in Product Design}

\section{Abstract:}

In order to improve the quality of life of the population and the future availability of raw materials and energy, design projects have adopted ecological criteria that are increasingly rigorous in their development. An example of practice that has been growing in parallel with the advancement of science is the use of new ecologically correct materials. In addition to contributing to the environment, this practice is an excellent tool for innovation. In this context, a material that has aroused worldwide interest of researchers of diverse areas is the bamboo. Its particular composition, superior properties to various traditional materials and low cost make it an excellent alternative material with strong sustainable and economical potential.

With bamboo as the main material of this work, we sought to develop new sustainable materials through the production of two types of bamboo biocomposites and polyurethane resin derived from castor oil. The biocomposites were manufactured using the Glued Laminated Bamboo (BLaC) technique and a new technique named BSFB (Sandwich Bamboo Fiber Biocomposite) which is a "sandwich" type biocomposite with manual lamination of the fibers obtained by processing the residues generated during the manufacturing of BLaC. Both biocomposites used the castor-based resin in their composition and resulted in non-toxic, light, and resistant materials; whose processing, besides simple and of low cost, provided excellent finishing. Specifically for this work, two prototypes were selected to exemplify the application of the biocomposites, namely: Protebam - Transtibial Endoskeletal Prosthesis and the Ocala sunglasses line. 


\section{Referências bibliográficas}

ABMACO. Compósitos 1 - Materiais, processos, aplicações, desempenhos e tendências. São Paulo: ABMACO, 2009.

AGARWAL, B. D.; BROUTMAN, L. J. Analysis and Performance of Fiber Composites. New York: John Wiley \& Sons, Inc., 1990.

AL-QURESHI, H. A. The design and development of Automotive Body from natural fiber reinforced composites. Int. Conf. on Composites 102 engineering, ICCE/4. Big Island of Hawai: [s.n.]. 1997. p. 95-96.

AMERICAN SOCIETY FOR TESTING AND MATERIALS. Standard Terminology for Composite Materials. American Society for Testing and Materials. West Conshohocken. 2007. (D3878-07).

AMERICAN SOCIETY OF METALS. ASM Handbook - Composites. Materials Park, Ohio. v. 21, 2001.

ASHBY, M. F.; JOHNSON, K. Materials and design: the art and science of material selection in product design. Amsterdam: Elsevier/Butterworth- Heinemann, 2010.

ASHBY, M. F.; JONES, D. R. H. Engenharia de materiais. Rio de janeiro: Elsevier, 2007.

BARELLI, B. G. P. Design para sustentabilidade: modelo de cadeia produtiva do bambu laminado colado (BLC) e seus produtos. Dissertação (Mestrado). 152 f. Unesp - Bauru, 2009.

BERALDO, A. L.; AZZINI A. Bambu: características e aplicações Ed. Agropecuária, Guaíba, 2004.

BEYLERIAN, G. M.; DENT, A. Ultra materials: how materials innovation is changing the world. Kingdom: Thame \& Hudson, 2007.

CANGEMI, J. M. Biodegradação de PU derivado do óleo de mamona, Tese de Doutorado, Instituto de Química de São Carlos, Universidade de São Paulo, Brasil, 2006.

CARVALHO, L. H. Chemical modification of fibers for plastics reinforcement in composites, First International Lignocelluloses Plastics Composites, São Paulo, 1996.

DIAS, M. R. A. C. Percepção dos materiais pelos usuários: modelo de avaliação permatus. Tese (Doutorado em Engenharia e Gestão do Conhecimento) - Universidade Federal de Santa Catarina, Florianopolis, 2009.

FIKSEL, J. Design for environment: creating eco-efficient products and processes. New York: McGraw-Hill, 1996.

FOWLER, P. A.; HUGHES, J. M.; ELIAS, R. M. Biocomposites: technology, environmental credentials and market forces. Journ. Scien. Food. Agric., v. 86, n. 12, p. 1781-1789, 2006.

GAGLIARDO, D. P.; MASCIA, N. T. Análise de estruturas sanduíche: parâmetros de projeto. Ambient. constr. (Online), Porto Alegre, v. 10, n. 4, p. 247-258, Dec 2010.

GODOY, J. Estudo de um novo compósito madeira / resina poliuretano para o desenvolvimento de um isolador híbrido. Dissertação (Mestrado). Escola de Engenharia de São Carlos. Universidade de São Paulo, 2007.

GRECO, T.M., CROMBERG, M. Bambu: cultivo e manejo.183 p. Insular, 2011.

HIDALGO-LÓPEZ, O. Bamboo the gift of the gods. D'Vinni Ltda: Bogotá, 2003.

IRVIN, G. M. The glass transition of lignin and its relevance to thermomechanical pulping. CSIRO Division of Chemical Technology Research Review, 1980.

JANSSEN, J. J. A. Designing and building with bamboo. Beijng, China: International Network for Bamboo and Rattan, 2000.

KHALIL, H. P. S. A. et al. Bamboo fibre reinforced biocomposites: A review. Materials \& Design, v. 42, p. 353-368, 2012.

LIESE, W. The anatomy of bamboo culms. INBAR - International Network for bamboo and rattan, Technical Report, p.204, 1998. 
LUNGBERG, L. Y. Materials selection and design for development of sustainable products. Materials \& Design, v. 28, n. 2, p. 466-479, 2007.

LÖBACH, B. Design industrial: bases para a configuração dos produtos industriais. Tradução Freddy Van Camp. - São Paulo: Edgard Blücher, 2001.

MAHAJAN, G.V.; AHER, V. S. Composite Material: A review over current development and automotive application. International Journal of Scientific and Research Publications, Volume 2, Issue 11, 2012.

MANRÍQUEZ, M. J.; MORAES, P. D. Comportamento da madeira a temperaturas elevadas. Revista Ambiente Construído, v. 9, p. 158-174, 2009.

MANZINI, E. The material of invention. London: The design council, 1989.

NELSON, P. M. et al. Caracterização física e térmica de compósito de poliuretano derivado de óleo de mamona associado com partículas de bambu. Polímeros, São Carlos, v. 23, n. 2, p. 201-205, 2013.

PEIXOTO, L. K. O potencial construtivo do bambu e as vantagens do laminado colado a partir deste insumo. In: SEMINÁRIO NACIONAL DA REDE BRASILEIRA DO BAMBU, 2. Rio Branco. Anais do $2^{\circ}$ Seminário Nacional da Rede Brasileira do Bambu, Rio Branco, 2010, p.129-142.

PELLICANO, M.; PACHEKOSKI, W.; AGNELLI, J. A. M. Influência da adição de amido de mandioca na biodegradação da blenda polimérica PHBV/Ecoflex®. Polímeros, São Carlos, v.19, n.3, p. 212-217, 2009.

PEREIRA, M. R.; BERALDO, A. L. Bambu de corpo e alma. Bauru: Canal, v. 6, p. 231, 2007.

RAMOS, B.P.F. Metodologia de curvatura de bambu laminado colado (BLaC) para fabricação de mobiliário - diretrizes para o design. 114 f. : il. Dissertação (Mestrado) - Universidade Estadual Paulista. Faculdade de Arquitetura, Artes e Comunicação, Bauru, 2014.

RIVERO, L. A. Laminado Colado e Contraplacado de Bambu, Dissertação de mestrado, Faculdade de Engenharia Agrícola, Universidade Estadual de Campinas, São Paulo, 2003.

ROZENFELD, $\mathrm{H}$. et al. Gestão de desenvolvimento de produtos: uma referência para a melhoria do processo. São Paulo: Saraiva, 2006.

SCURLOCK, J. M. O.; DAYTON, D. C.; HAMES, B. Bamboo: An Overlooked Biomass Resource? Biomass \& Bioenergy. 2000. 229-44.

SILVA, C. D.; JÚNIOR, R. C. S.; AQUINO, E. M. F. Influência da presença de fibras naturais em compósitos híbridos, tipo sanduíche. Congresso Nacional de Engenharia Mecânica (CONEM), Belém, PA, 2004.

TALABGAEW, S.; LAEMLAKSAKUL, V. Experimental studies on the mechanical property of laminated bamboo in Thailand. World Academy of Sci Eng and Technol, v. 34, p. 327-331, 2007.

TARGA, G. N. Compósito reforçado por laminado de bambu com matriz de poliuretano e epóxi. Dissertação (Mestrado). Universidade Federal de Santa Catarina, 2011. 